\section{Use of digitalised continuous endotracheal tube cuff pressure monitoring in anterior cervical spine surgery}

Sir,

Anterior cervical discectomy and fusion (ACDF) is a surgery performed for prolapse of intervertebral disc. ACDF involves retraction of the anterior cervical soft tissue to expose the anterior vertebral column. Application of cervical retractors may increase the cuff pressure of endotracheal tube (ETT), which may lead to hoarseness of voice, sore throat, dysphagia and vocal cord palsy. ${ }^{[1]}$ Incidence of tracheal ischaemia after ACDF has been reported to be $2-44 \% .{ }^{[1]}$

ETT cuff pressure monitoring and maintaining it between 20 and $30 \mathrm{cmH}_{2} \mathrm{O}$ has been recommended and widely followed ${ }^{[2]}$ In routine practice, after intubation, ETT cuff pressure is manually inflated to $20-30 \mathrm{cmH}_{2} \mathrm{O}$ using a Posey Cufflator. The cuff pressure is measured immediately after positioning and also after placement and removal of the self-retaining retractors. ${ }^{[3]}$

However, the time between the application of temporary manual retractors and self-retaining retractor is significant during which ETT cuff pressure may raise, which goes unmonitored. Adding to this, the periodic checking of cuff pressure during the procedure involves disturbing the drapes and the operating field to reach the ETT cuff, which can be inconvenient.

Here, we report a simple and convenient way of monitoring the ETT cuff pressure continuously during ACDF procedures. Anaesthesia technique used was general anaesthesia with oxygen, air and sevoflurane with fentanyl and atracurium infusion for all cases. Nitrous oxide was not used as it increases the cuff pressure and could have interfered with the study. Continuous ETT cuff pressure was recorded by connecting the pilot balloon of the ETT to a $100 \mathrm{~cm}$ extension tubing with a three-way stopcock along with an air-filled transducer [Figure 1]. A Posey Cufflator [Figure 2] was inserted into the other port of the same three-way connector. The transducer was connected to an IntelliVue 24 cardiac monitor, with a pressure module. The transducer was initially zeroed to atmospheric pressure, and the real-time cuff pressure waveform was displayed on the monitor [Figure 3].

This technique has been described by Doyle ${ }^{[4]}$ and validated by Sole et al. ${ }^{[5]}$ Any change in cuff pressure was

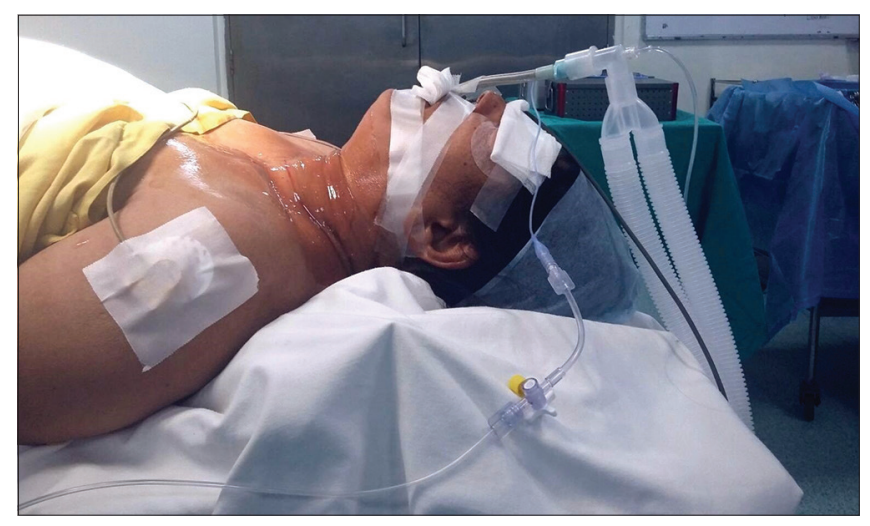

Figure 1: Endotracheal tube cuff connected to air-filled pressure transducer via stopcock

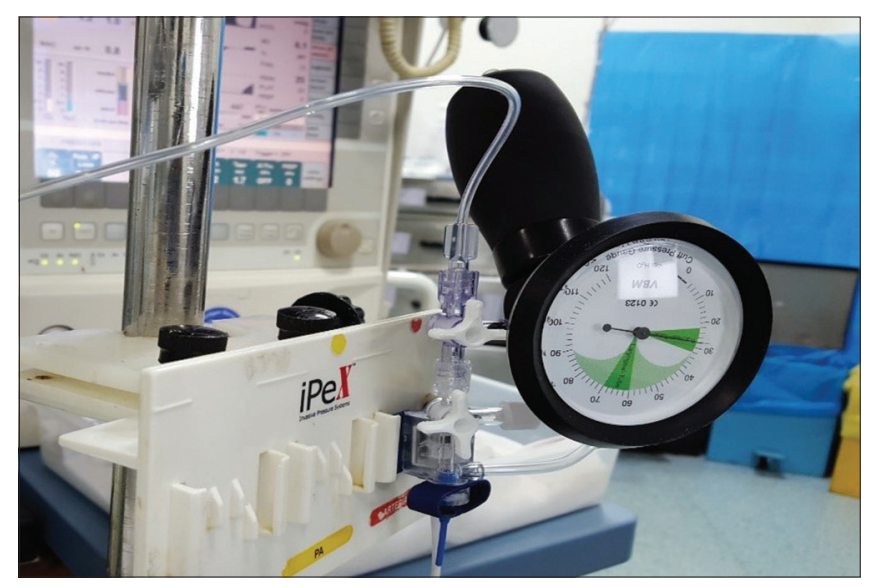

Figure 2: Posey Cufflator attached at the other end of stopcock

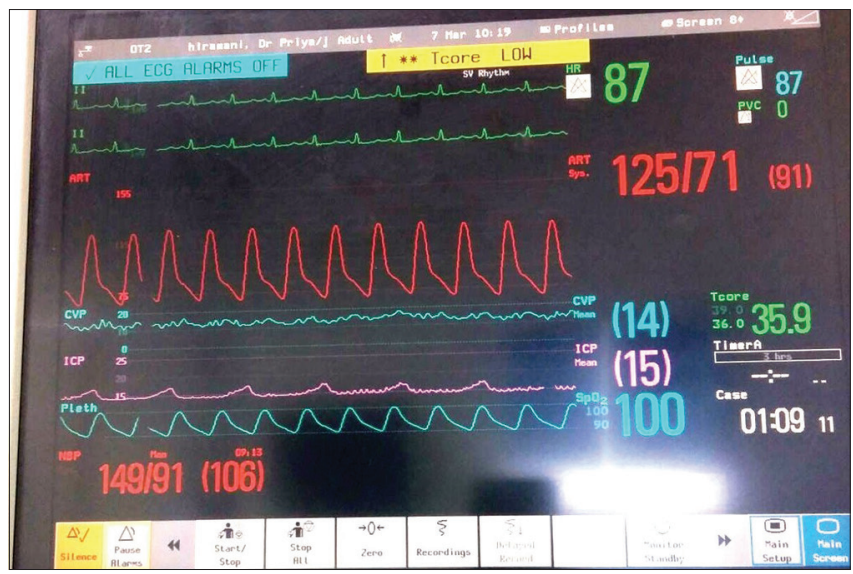

Figure 3: Real-time graphical display of cuff pressure in $\mathrm{mmHg}$ (pink graph indicated as intracranial pressure) 


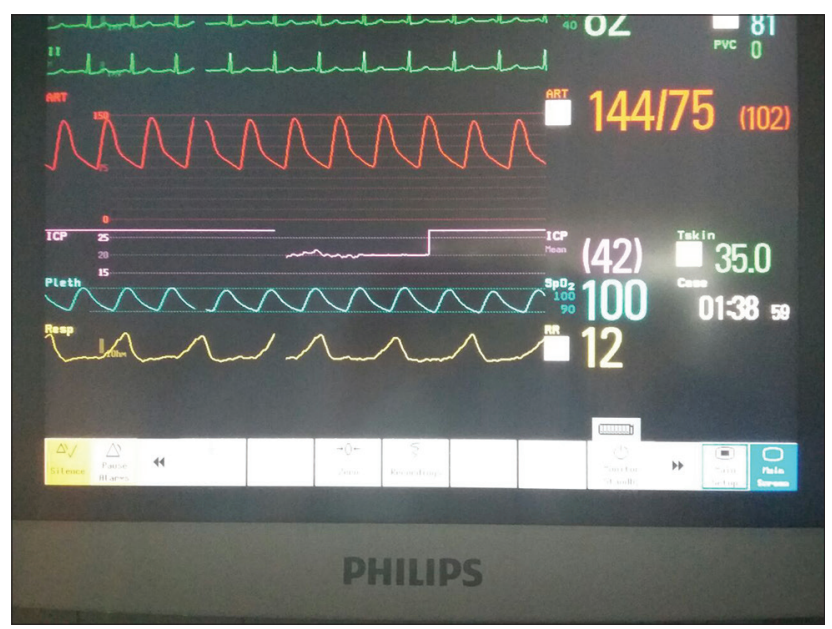

Figure 4: Graph showing elevated cuff pressure (pink graph indicated as intracranial pressure)

noticed and corrective measures (informing the surgeon or adjusting the cuff pressure using Posey Cufflator) were taken. Values obtained with the cufflator and transducer were congruent.

The continuous online display of cuff pressure changes [Figure 4] allows us to maintain the cuff pressure between 20 and $30 \mathrm{cmH}_{2} \mathrm{O}$ at every point of the surgery which is essential ${ }^{[1]}$ and to do it without any struggle to reach the ETT cuff itself. This method of continuous pressure monitoring could reduce the incidence of tracheal ischaemia and post-operative complications in patients undergoing ACDF procedures.

\section{Declaration of patient consent}

The authors certify that they have obtained all appropriate patient consent forms. In the form the patient(s) has/ have given his/her/their consent for his/her/their images and other clinical information to be reported in the journal. The patients understand that their names and initials will not be published and due efforts will be made to conceal their identity, but anonymity cannot be guaranteed.

\section{Financial support and sponsorship} Nil.

\section{Conflicts of interest}

There are no conflicts of interest.

\section{Priya Motiani, Murali Chakravarthy, Keshava Reddy, Jeevan Kumar}

\author{
Department of Anesthesia, Critical Care and Pain Relief, \\ Fortis Hospitals, Bengaluru, Karnataka, India \\ Address for correspondence: \\ Dr. Priya Motiani, \\ 513, A Block, C Wing, Esteem Enclave Apartments, Bannerghatta \\ Road, Arekere, Bengaluru - 560 076, Karnataka, India. \\ E-mail: motianidrpriya@gmail.com
}

\section{REFERENCES}

1. Kim SW, Shin H. Postoperative tracheal mucosa ischemia by endotracheal cuff pressure change during the anterior cervical spine surgery. J Korean Neurosurg Soc 2006;39:419-22.

2. Garg R, Rath GP, Bithal PK, Prabhakar H, Marda MK. Effects of retractor application on cuff pressure and vocal cord function in patients undergoing anterior cervical discectomy and fusion. Indian J Anaesth 2010;54:292-5.

3. Arts MP, Rettig TC, Vries JD, Wolfs JF, Veld BA. Maintaining endotracheal tube cuff pressure at $20 \mathrm{mmHg}$ to prevent dysphagia after anterior cervical spine surgery; protocol of a double-blind randomised controlled trial. BMC Musculoskelet Disord 2013;14:280.

4. Doyle DJ. Digital display of endotracheal tube cuff pressures made simple. Anesthesiology 1999;91:329.

5. Sole ML, Penoyer DA, Su X, Jimenez E, Kalita SJ, Poalillo E, et al. Assessment of endotracheal cuff pressure by continuous monitoring: A pilot study. Am J Crit Care 2009;18:133-43.

This is an open access article distributed under the terms of the Creative Commons Attribution-NonCommercial-ShareAlike 3.0 License, which allows others to remix, tweak, and build upon the work non-commercially, as long as the author is credited and the new creations are licensed under the identical terms.

\begin{tabular}{|l|l|}
\hline \multicolumn{2}{|c|}{ Access this article online } \\
\hline Quick Response Code: & Website: \\
\hline & www.jnaccjournal.org \\
\hline & \\
\hline
\end{tabular}

How to cite this article: Motiani $\mathrm{P}$, Chakravarthy M, Reddy K, Kumar J. Use of digitalised continuous endotracheal tube cuff pressure monitoring in anterior cervical spine surgery. J Neuroanaesthesiol Crit Care 2016;3:272-3. 